\title{
Impact of climate change on ozone-related mortality and morbidity in Europe
}

\author{
Hans Orru*,\#, Camilla Andersson ${ }^{\star}$, Kristie L. Ebi ${ }^{+}$, Joakim Langner", \\ Christofer Åström* and Bertil Forsberg*
}

ABSTRACT: Ozone is a highly oxidative pollutant formed from precursors in the presence of sunlight, associated with respiratory morbidity and mortality. All else being equal, concentrations of ground-level ozone are expected to increase due to climate change.

Ozone-related health impacts under a changing climate are projected using emission scenarios, models and epidemiological data. European ozone concentrations are modelled with the model of atmospheric transport and chemistry (MATCH)-RCA3 $(50 \times 50 \mathbf{~ k m})$. Projections from two climate models, ECHAM4 and HadCM3, are applied under greenhouse gas emission scenarios A2 and A1B, respectively. We applied a European-wide exposure-response function to gridded population data and country-specific baseline mortality and morbidity.

Comparing the current situation (1990-2009) with the baseline period (1961-1990), the largest increase in ozone-associated mortality and morbidity due to climate change (4-5\%) have occurred in Belgium, Ireland, the Netherlands and the UK. Comparing the baseline period and the future periods (2021-2050 and 2041-2060), much larger increases in ozone-related mortality and morbidity are projected for Belgium, France, Spain and Portugal, with the impact being stronger using the climate projection from ECHAM4 (A2). However, in Nordic and Baltic countries the same magnitude of decrease is projected.

The current study suggests that projected effects of climate change on ozone concentrations could differentially influence mortality and morbidity across Europe.

KEYWORDS: Environment, hospitalisation, ozone

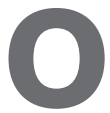
zone is one of the most important air pollutants. It is formed in photochemical reactions, with concentrations affected by weather and the supply of chemical precursors, including nitrogen oxides $\left(\mathrm{NO}_{\mathrm{X}}\right)$, volatile organic compounds (VOCs), methane $\left(\mathrm{CH}_{4}\right)$ and carbon monoxide (CO). Climate change can affect ozone concentrations and thus influence respiratory health [1] through a number of processes, including chemical production, and dilution and deposition of ozone, that are regulated by temperature, cloud cover, humidity, wind and precipitation [2-4]. Ozone is also formed from reactions that include natural biogenic emissions; these reactions also depend on temperature and solar radiation, and thereby cloud cover. Although there is high confidence in projected changing temperatures [5], changes in other meteorological parameters, such as precipitation and cloud cover, are more uncertain. There is also great uncertainty in how natural vegetation will respond to climate change.

Extreme weather events such as heatwaves (observed in Europe in 2003 and 2006) can further increase ground-level ozone concentrations [6, 7]. During the 2003 heatwave, the relative contributions of temperature to adverse health effects in France ranged from $97.5 \%$ in Bordeaux to $14.7 \%$ in Toulouse, where air pollution and ozone singly and jointly contributed to mortality [6]. Chemical transport models project widespread temperaturerelated summertime increases of ground-level ozone in polluted regions of Europe, North America and Asia. The sensitivity of ground-level ozone to climate change is particularly high in urban areas, reflecting the concentration of precursors for ozone formation. The frequency of stagnation episodes is projected to increase over northern mid-latitude continents and the ventilation is projected to decrease in Europe, eastern North America and East Asia [8].

Climate change may lead to higher biogenic VOC emissions [9]. Warmer temperatures might lead to increasing soil microbial activity that may cause an increase in $\mathrm{NO}_{\mathbf{X}}$ emissions and a consequent increase in ozone amounts [10]. Methane emissions promote tropospheric ozone formation and global climate change [11]. Climate change and
AFFILIATIONS

${ }^{*}$ Dept of Public Health and Clinical Medicine, Umeå University, Umeå, and "Swedish Meteorological and Hydrological Institute, Norrköping, Sweden.

\# Dept of Public Health, University of Tartu, Tartu, Estonia. ${ }^{+}$ClimAdapt, Los Altos, CA, USA.

CORRESPONDENCE

H. Orru

Dept of Public Health University of Tartu Ravila 19

Tartu

50411

Estonia

E-mail: Hans.Orru@ut.ee

Received:

Dec 012011

Accepted after revision: June 022012

First published online:

June 272012

European Respiratory Journal Print ISSN 0903-1936 Online ISSN 1399-3003 
increasing temperature could also affect the risk of wildfires [12]. Due to the emissions of precursors such as CO, the 2007 California fires, for instance, caused a three-fold exceedance of the limit values for ozone in the region [13].

Epidemiological studies have shown a broad range of effects of ground-level ozone on health, leading to excess daily mortality and morbidity. Significant negative health effects have been demonstrated for different causes, mainly for respiratory and (to a lesser extent) cardiovascular diseases [14]. The majority of epidemiological studies concentrated on acute health consequences (due to short-term very high concentrations of ozone). For instance, the association between acute exposures of ozone and short-term mortality has been shown in several studies [1518]. There are several large multi-city studies relating the numbers of hospital admissions for respiratory diseases [19] and chronic obstructive pulmonary disease [20] to ambient ozone levels. Exposure to ozone has been shown to increase the likelihood of wheeze, chest tightness and asthma [21]. The other main effects include emergency department visits for asthma, respiratory tract infections and exacerbations of existing airway diseases [22], as well as the decline of lung function [23].

Epidemiological evidence of the chronic effects of ground-level ozone is less conclusive. Chronic exposures could induce significant changes in airways and systemic inflammation. A recent study by JERRETT et al. [24] showed significant increases in the risk of death from respiratory causes in association with an increase in ozone concentration. However, the risk of death from cardiovascular causes was not any more significant when the concentration of particles with a $50 \%$ cut-off aerodynamic diameter of $2.5 \mu \mathrm{m}$ was taken into account. The summer ozone average was associated with survival in four cohorts of persons with chronic conditions that might predispose to ozone effects, such as congestive heart failure [25]. Other studies indicate some cardiovascular effect that may be due to systemic inflammation responses and alterations of the cardiac rhythm. CHUANG et al. [26] found that increases in inflammatory markers in the blood and a decrease in heart rate variability associated with elevated levels of ozone lagged over 1-3 days in young and healthy adults. In some Asian studies, ozone exposure has been associated with increasing mortality due to stroke [27]. The mortality risk exhibited a seasonal variation, being more intense during periods of warmer weather.

A few studies have projected the effects of climate change on ground-level ozone concentrations and the subsequent effects on public health [28-36]. Four of these studies were published in the review by EBI and MCGREGOR [37]; three focused on the USA and one on the UK. Although using different greenhouse gas emission scenarios and models, the US studies by CHANG et al. [33] and TAGARIs et al. [34] concluded that climate change is projected to increase ozone concentrations by the 2050s, resulting in increased ozone-related mortality, with more premature deaths in the southern states. A third US study focused on childhood asthma emergency-department visits in the New York City metropolitan area [36], using the same ozone projections as KNOWLTON et al. [28]. The UK study compared changes in ground-level ozone assuming A2 scenario emissions $(+15 \%)$ to changes assuming current legislation and air quality standards in the future $(+6 \%)$ to changes assuming maximum feasible reductions $(-5 \%)$ [35]. Ozone concentrations in 10 world regions, assuming A2 emissions and current baseline mortality rates, are projected to increase by 9.2 parts per billion by volume (ppbv) as a global population-weighted daily 8-h maximum between the years 2000 and 2030 [32]. For Europe the population weighted mean is projected to increase by $4.7 \mathrm{ppbv}$.

Impact assessments have estimated the health impacts of historic versus current ground-level ozone concentrations. ANENBERG et al. [38] estimated anthropogenic ground-level ozone concentrations and related health impacts, and found that assuming a low concentration threshold ( $25 \mathrm{ppbv})$ has a large impact on the estimated impact on mortality. Moreover, they found that comparing the year 2000 to 1860, ozone concentrations increased by a factor of two or three, depending on the region of world assessed. For Europe, the modelled annual average concentration increased from 18.26 to $48.92 \mathrm{ppbv}$, with the current concentrations in Europe expected to cause $0.041 \pm 0.021$ million or $0.023 \pm 0.017$ million excess respiratory mortalities annually, depending on the threshold assumed.

The current study assesses the impacts of climate change on ozone-related mortality and morbidity in Europe over wider time-periods than often used. Furthermore, it illustrates the impact of applied greenhouse gas emission scenarios and global climate models on projected health impacts.

\section{MATERIAL AND METHODS}

Data on ozone exposure, baseline mortality, morbidity and population were generated for the health impact assessment.

European ozone concentrations were modelled at a grid size of $50 \times 50 \mathrm{~km}$ using the model of atmospheric transport and chemistry (MATCH) [4, 39] which models about 130 chemical reactions between 70 chemical components, including thermal and photochemical reactions, wet chemistry and secondary particle formation. Species at the lateral and top boundaries of MATCH were kept at levels representative for the year 2000 throughout the simulated years. MATCH simulates biogenic emissions of isoprene based on hourly temperature and solar radiation. Biogenic emissions of isoprene also depended on the geographical distribution of vegetation types, which was held constant throughout the simulations. This is a simplification, but reliable projections of vegetation linked to climate projections are unavailable. Anthropogenic precursor emissions of NOx, sulfur oxides, CO, non-methane VOCs and ammonia from the European Monitoring and Evaluation Programme (www.ceip. at) for the year 2000 were used as input to MATCH. These anthropogenic emissions were emitted with seasonal, weekly and daily variation at year 2000 levels for all simulated years. MATCH uses meteorology produced by the regional climate model RCA3 [40, 41]. Projections from two global climate models, ECHAM4 and HadCM3 under greenhouse gas emission scenarios $\mathrm{A} 2$ and $\mathrm{A} 1 \mathrm{~B}$, respectively, were used as input to RCA3, which in turn produced a dynamical downscaling of the climate over Europe at a higher resolution. With ECHAM4 (A2), two previously presented periods were compared [42, 43]: the baseline period 1961-1990 and future 2021-2050 (MATCHRCA3-ECHAM4). With HadCM3 (A1B), two additional periods were included [44, 45]: the current situation 1990-2009 and further in the future, 2041-2060 (MATCH-RCA3-HadCM3). These model parameters have been extensively evaluated within the given references. 
Different emission scenarios of greenhouse gases were used in the two climate projections downscaled by RCA3. However, the European average temperature changes are quite similar for the two simulations between 1961-1990 and 2021-2050 using the HadCM3 (A1B) and ECHAM4 (A2) projection, $2.1^{\circ} \mathrm{C}$ and $1.9^{\circ} \mathrm{C}$, respectively. Warming is somewhat stronger in HadCM3 because HadCM3 has a stronger response to greenhouse gas forcing. The resemblance is partly explained by the limited difference in anthropogenic greenhouse gas emissions for the period 2021-2050 between the A1B and A2 scenarios. Projected $\mathrm{CO}_{2}$ concentrations for 2010 in $\mathrm{A} 1 \mathrm{~B}$ and $\mathrm{A} 2$ are close to current (2010) observed $\mathrm{CO}_{2}$ concentrations. The projected changes in $\mathrm{CO}_{2}$ emissions are larger towards the end of the 21st century, with a bigger difference between $\mathrm{A} 1 \mathrm{~B}$ and $\mathrm{A} 2$ which results in larger differences in the simulated temperature change between 1961-1990 and $2071-2100,3.8^{\circ} \mathrm{C}$ and $4.3^{\circ} \mathrm{C}$ using HadCM3 and ECHAM4, respectively. The two climate projections have the second and fourth highest average temperature change for the period 2040-2070 in a group of 13 different projections downscaled from different global climate model runs by RCA3 throughout Europe using the A1B or A2 scenario [46]. Even though differences in mean temperature change until 2050 are not large there are other differences between the two projections on the regional scale within Europe. In particular, the reduction in precipitation in summer, and consequently cloud cover and soil moisture, is larger in southwestern Europe in ECHAM4 (A2). These factors are important for ozone production and dry deposition to vegetation.

Ozone exposure measured by SOMO35 (the sum of ozone daily 8-h maximum means $>35$ ppbv in the calendar year, expressed in $\mu \mathrm{g} \cdot \mathrm{m}^{-3}$ per day) were calculated with a geographical resolution of $50 \mathrm{~km}$. Hence, the health effects were calculated for levels $>35 \mathrm{ppbv}\left(70 \mu \mathrm{g} \cdot \mathrm{m}^{-3}\right)$. Often the cut-off value of $70 \mu \mathrm{g} \cdot \mathrm{m}^{-3}$ is used in risk assessments, as a statistically significant increase in mortality risk estimates has been observed at daily ozone concentrations $>50-70 \mu \mathrm{g} \cdot \mathrm{m}^{-3}[47,48]$. As a sensitivity analysis we also used cut-off values of SOMO50 and SOMO25. To see the seasonal impacts, the $\mathrm{SOMO} 35$ values and their expected health impacts were calculated separately for summer and winter. The population average exposures were calculated from country impact estimates.

The data on mortality and hospitalisation were obtained from the World Health Organization (WHO) European Health for All database (http://data.euro.who.int/hfadb). The crude nonstandardised all-cause mortality and respiratory hospitalisation rates were used. Average rates for 2000-2005 were calculated for all countries and applied to all grids within each country. The shape of national borders was used to determine to which country each grid cell belonged.

The gridded population data for Europe in 2000 were taken from the History Database of the Global Environment (HYDE) theme within the Netherlands Environmental Assessment Agency [49].

For the calculation of mortality and morbidity cases $(\Delta Y)$ in absolute and relative numbers the following equation was used:

$$
\Delta Y=\left(Y_{0} \times p o p\right) \times\left(e^{\beta \times X}-1\right)
$$

where $Y_{0}$ is the baseline mortality or morbidity rate; pop the number of exposed persons; $\beta$ the exposure-response function (relative risk); and $X$ the estimated excess exposure.

In order to describe the effects of ozone on mortality, the WHO meta-analysis relative risk of 1.003 per $10 \mu \mathrm{g} \cdot \mathrm{m}^{-3}$ increase in the maximum daily 8 -h average ozone concentration $(95 \% \mathrm{CI}$ 1.001-1.004) was used as the exposure-response coefficient (ERC) [14]. The same meta-analysis estimated the ERC of respiratory hospitalisations for adults (15-64 yrs) as 1.001 (95\% CI 0.991-1.012) and for older adults ( $\geqslant 65 \mathrm{yrs}$ ) as 1.005 (95\% CI $0.998-1.012)$ per $10 \mu \mathrm{g} \cdot \mathrm{m}^{-3}$ increase in the maximum daily $8-\mathrm{h}$ average ozone concentration. However, because for most countries only the hospitalisation rates for all ages were available, the alternative ERC (1.003) was used. This combined the Committee on the Medical Effects of Air Pollutants [50] unofficial meta-analysis results (1.003, 95\% CI 1.000-1.007) and ERC, based on proportion of respiratory hospital admissions in different age groups (15-64 yrs and $\geqslant 65 \mathrm{yrs}$ ).

\section{RESULTS}

Climate change will affect ground-level ozone concentrations (fig. 1), through a number of processes, as described previously. Changing ozone concentrations will then affect mortality and respiratory hospital admissions (table 1). The baseline (recent) and current exposure to ground-level ozone above the applied threshold (SOMO35) is associated with a large number of premature deaths (approximately 26,000-28,000 per yr) and hospitalisations in Europe (tables 1 and 2). The largest impact is in southern European countries with large populations, such as Italy, Spain and France.

When the current situation (1990-2009) is compared with the baseline period (1961-1990) using the ozone estimates based on MATCH-RCA3-HadCM3, the largest climate change-driven relative increase in ozone-related mortality and hospitalisations is modelled to have occurred in Ireland, the UK, the Netherlands and Belgium (table 1); an increase of up to $5 \%$ is estimated. A decrease is estimated for the northernmost countries, with the largest decrease, by $5 \%$, in Finland. In absolute numbers, the model suggests 647 more deaths, and 867 excess hospitalisations per year in Europe with the largest numbers in Italy: 100 and 117, respectively.

If we compare the baseline period (1961-1990) with the future (2021-2050), the difference is even more dramatic for several countries (table 1). The increase in ozone-related cases is projected to be largest in Belgium, France, Spain and Portugal $(10-14 \%)$. However, in most Nordic and Baltic countries, there is a projected decrease in ozone-related mortality of the same magnitude. The change is stronger if we compare the further future (2041-2060) with the baseline period (1961-1990) as simulated using HadCM3 (A1B). The projected impacts are larger using the ECHAM4 (A2) projection, up to $34 \%$ increase in Belgium, due to a stronger reduction in summer precipitation in this region and corresponding reductions in cloudiness and soil moisture leading to higher ozone concentrations.

We also investigated the magnitude of the impact of climate change-induced changes in ground-level ozone concentration on the total all-cause mortality and on the total rate of respiratory hospitalisations. Because the ERCs for total mortality and respiratory hospitalisation are of the same magnitude 

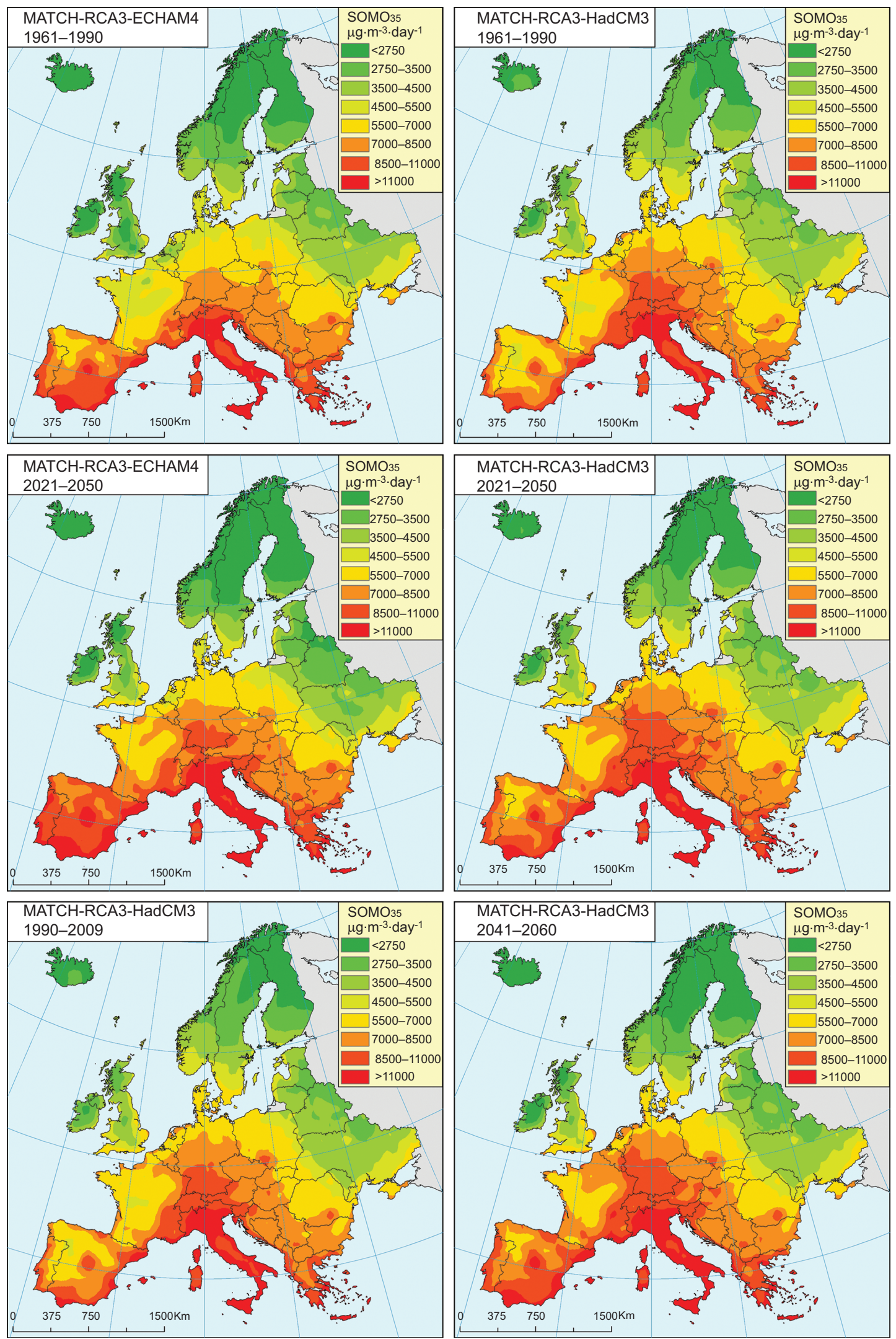

FIGURE 1. Change in the sum of SOMO35 (ozone daily 8-h maximum means $>35 \mathrm{ppb}$ (volume) values in the calendar year) due to climate change-induced ozone exposure variations. MATCH: model of atmospheric transport and chemistry. 


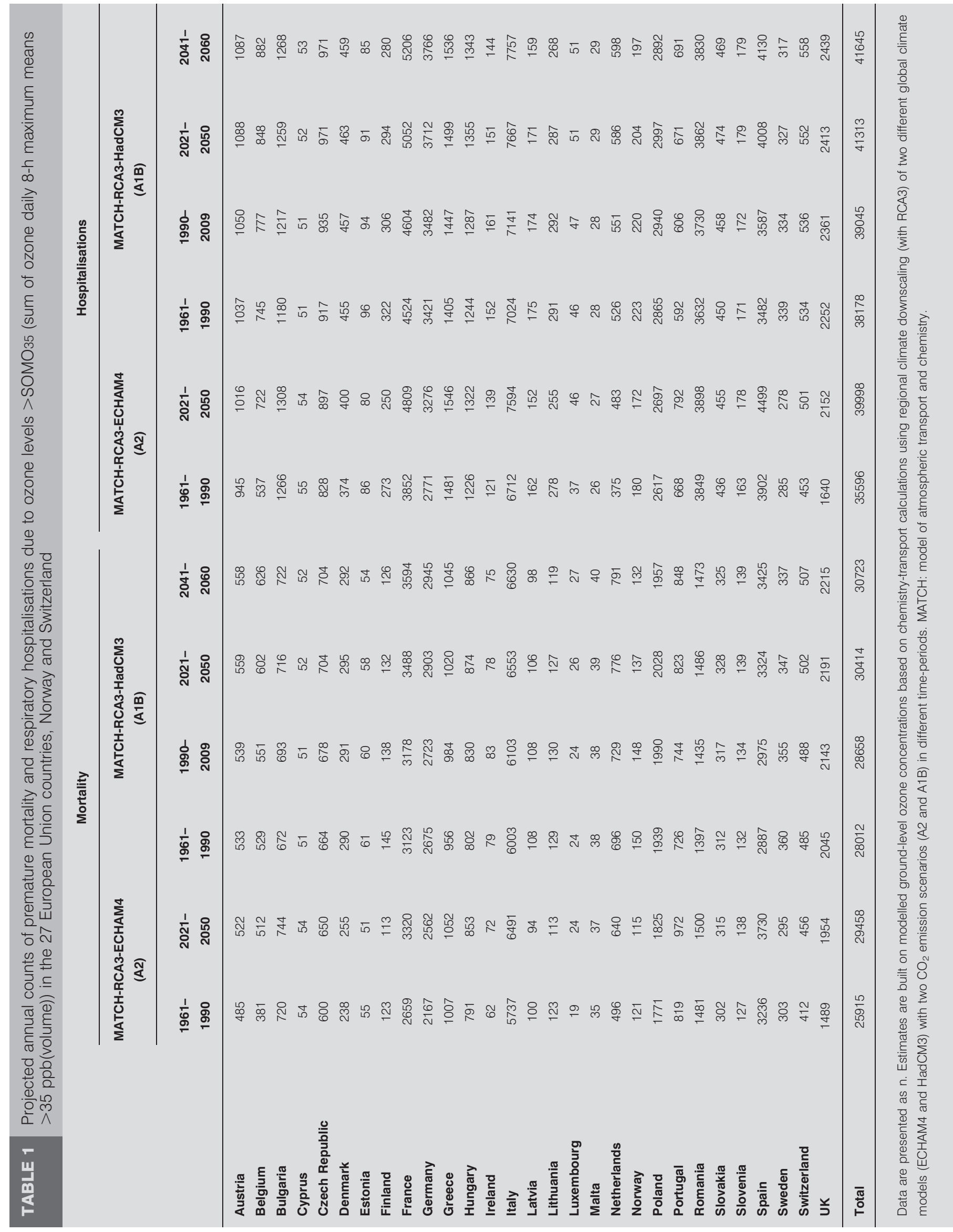




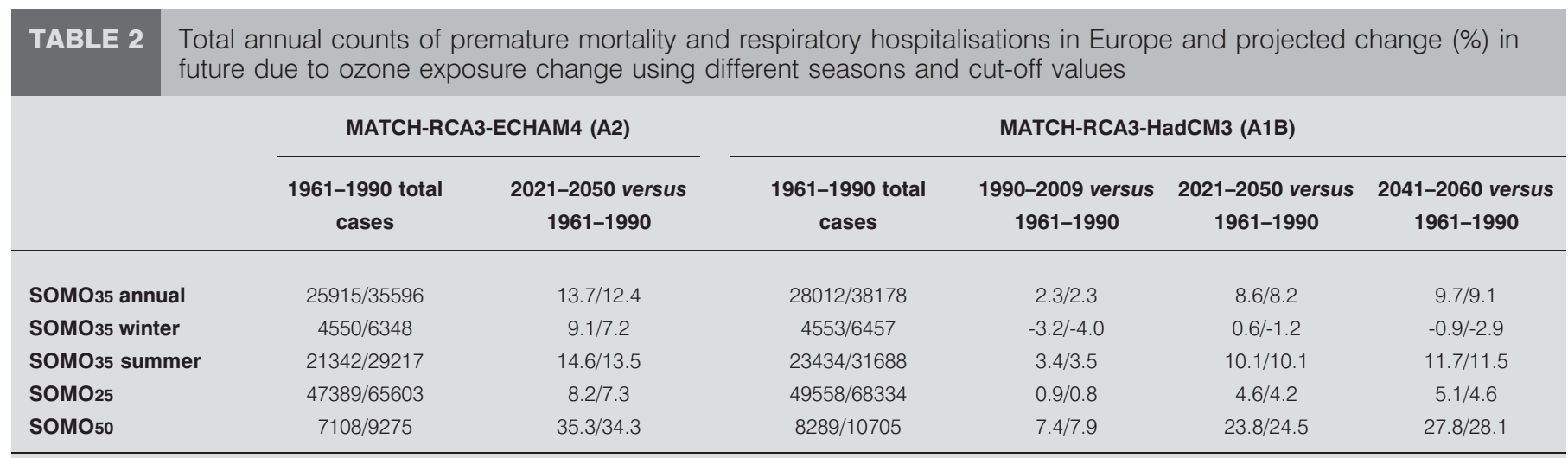

Data are presented as n or \%. SOMO: sum of ozone daily 8-h maximum means above a given level. MATCH: model of atmospheric transport and chemistry.

$\left(0.3 \%\right.$ per $10 \mu \mathrm{g} \cdot \mathrm{m}^{-3}$ increase in the maximum daily 8 -h mean ozone concentration), the impact would be the same in relative numbers but different in total numbers. The relative increase of all-cause mortality and respiratory hospitalisations in some areas of Spain, Italy and Portugal are expected to be $>0.2 \%$ in the future compared to baseline period rates (fig. 2). The effect is again larger using the ECHAM4 (A2) projection. Comparing the current period (1990-2009) with the baseline (1961-1990) and the further future (2041-2060) with baseline (1961-1990) using the HadCM3 (A1B) projection suggests that the majority of the impacts in the highest risk areas will happen in the future and only a smaller impact has already occurred (fig. 2). However, there is variability on decadal scale in the models as in reality, but the modelled and real world decadal variability do not necessarily correlate; in fact, the decadal variabilities may even be anti-correlated. This means that change over time-periods differing by one or a few decades simulated by climate models are not necessarily comparable to reality.

There are regional differences in the climate change projections (1961-1990 versus 2021-2050), depending on which global climate model (ECHAM4 or HadCM3) and $\mathrm{CO}_{2}$ emission scenario (A2 or A1B) were used as input to RCA3. For most countries, MATCH-RCA3-ECHAM4 (under the A2 scenario) produced larger increases; however, for some countries (e.g. Greece and Bulgaria), the increase is of the same magnitude in the MATCH-RCA3-HadCM3 scenario (under the A1B scenario). There are also differences in SOMO35 values in the baseline period (1961-1990) modelled with MATCH, based on the regional downscaling of the two global climate models, despite similar greenhouse gas emissions in the baseline period in the two realisations (fig. 1). This is due to differences in the model realisations of the current climate [51]. For some countries, e.g. Belgium, the Netherlands and the UK, the MATCH-RCA3HadCM3 scenario results in $>25 \%$ higher concentrations; whereas for southern European countries, e.g. Spain and Portugal, the SOMO35 values were $>10 \%$ lower compared to MATCH-RCA3-ECHAM4.

\section{DISCUSSION}

Ground-level ozone is a crucial public health issue. The ambient ozone concentrations in the northern hemisphere generally reach concentrations known to be harmful to health during large parts of every year [4]. The respiratory system has antioxidant defences that can mitigate to some extent the impacts of ozone exposure. Age, pre-existing diseases, social and economic status, habits, genetics and other factors affect individual thresholds for noticeable impacts. This variability obscures the determination of a clear no-effect exposure concentration at the population level. Individuals with underlying lung or airway diseases are at higher risk of adverse impacts, including wheeze, chest tightness, cough and asthma attacks. People with asthma and allergic rhinitis are somewhat more susceptible to transient alterations in respiratory function caused by acute exposure to ozone. Lung function decrease is more consistently observed in asthmatic children, especially those with low birth weight. At high concentrations, ozone also enhances airway responsiveness in healthy individuals. In the current assessment, health indicators are premature mortality and respiratory hospitalisations related to short-term exposure because there are available meta-coefficients for these outcomes. The actual health effects could be more severe, including effects on survival, but also affect a larger proportion of the population in terms of respiratory illness.

Exposure-response functions support the use of a cumulative SOMO metric to estimate health impacts $[12,44]$. The cut-off value used ( $35 \mathrm{ppbv}$ ) is below the WHO air quality guideline for ozone of maximum daily $8-\mathrm{h}$ average $100 \mu \mathrm{g} \cdot \mathrm{m}^{-3}$ [52] and the European Union air quality directive 2008/50/EC of maximum daily 8 -h average $120 \mu \mathrm{g} \cdot \mathrm{m}^{-3}$, and is not to be exceeded on $>25$ days per calendar year [53]. The same cut-off value has been used in other health impact assessments [54-56]. As epidemiological studies have also shown associations at lower concentrations [48,57], by using this cut-off value the total number of cases attributed to ozone are probably underestimated in all scenarios. Using $\mathrm{SOMO}_{25}$ values as a cut-off would approximately double the number of attributed cases, but decrease the projected relative increase (table 2). However, using the higher cut-off of SOMO50 would significantly decrease the number of cases, but increase the relative changes (table 2), since the largest increase appeared among high-ozone days (maximum daily $8-\mathrm{h}$ average $>100 \mu \mathrm{g} \cdot \mathrm{m}^{-3}$ ). Most of the projected increase in SOMO35 is during summer, AprilSeptember (table 2).

Our results on the numbers of current ozone-induced mortalities for Europe with different cut-off values (table 2) are very 

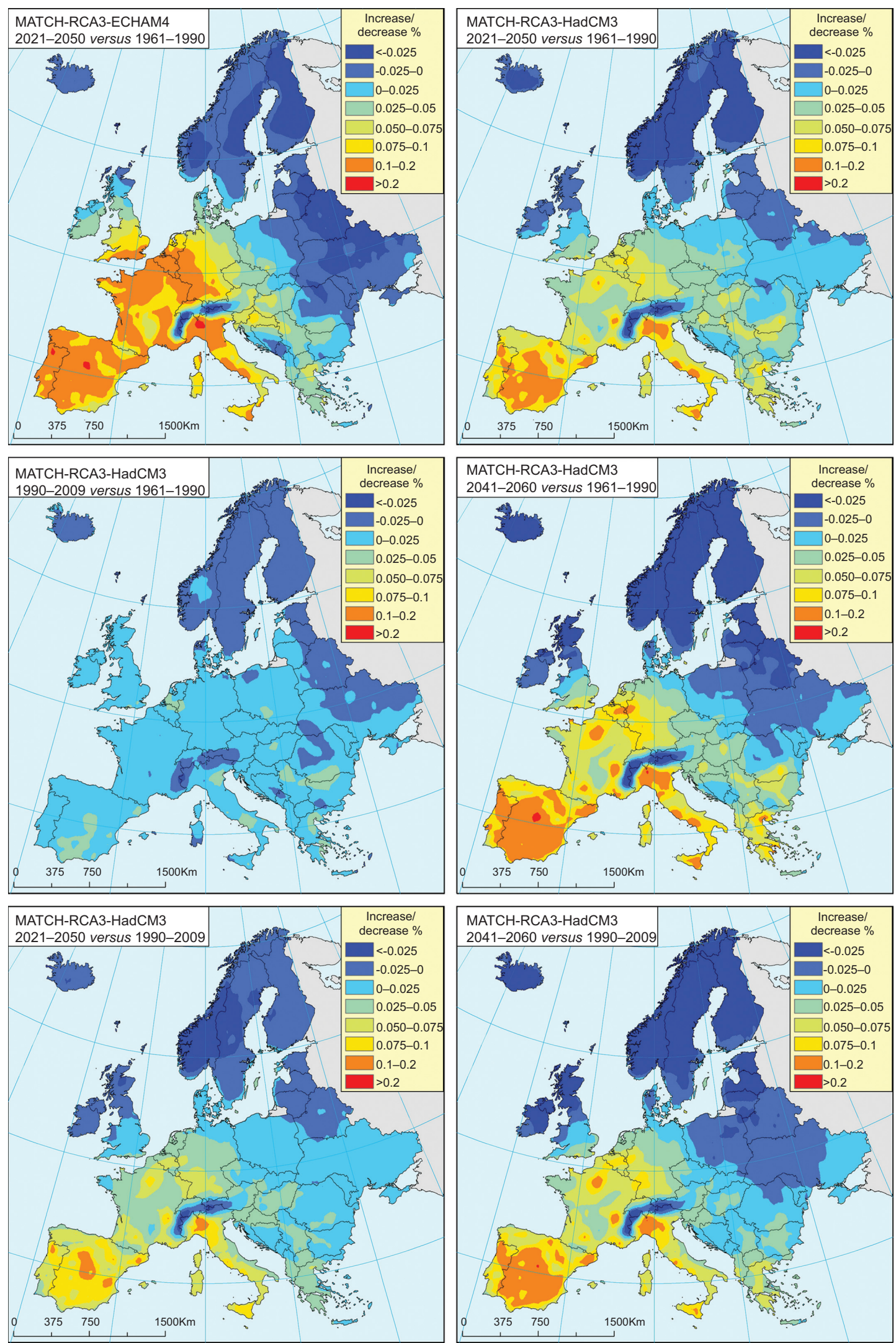

FIGURE 2. Change in all-cause mortality and respiratory hospitalisations (same relative change, \%) due to climate change-induced variations in ozone exposure. MATCH: model of atmospheric transport and chemistry. 
similar to the results from ANENBERG et al. [38], even though they used a "long-term" exposure-response relationship [24] while we use a more established "short-term" exposure-response relationship [14]. However, because long-term exposure may also induce chronic disease (such as asthma) and possible effects on survival, the size and kind of ozone-related health impacts could be more significant than we indicate. Recently, ozone exposure in Sweden and other countries has also been associated with pre-term birth, a risk factor for asthma [58].

We focused on the impacts of climate change-related alterations in ground-level ozone concentrations, holding other factors constant. Our results show that climate change could impact health in the future through higher ozone concentrations in several countries. An increase of up to $13.7 \%$ ozone-related mortality in Europe (with SOMO35), which translates into $0.2 \%$ in all-cause total mortality and respiratory hospitalisations, would affect the public health sector through increased healthcare costs. In some countries (e.g. northern Europe) reductions of ozone-induced mortality and hospitalisations are expected in the future due to climate change. Many processes contribute to the decrease in tropospheric ozone including increasing chemical destruction due to more water vapour, decreasing natural isoprene emissions, increased dry deposition and changing pollution transport patterns [43].

Comparing our current analysis with the Clean Air for Europe (CAFE) programme assessment for 2000 and 2020 [55], we found somewhat larger impacts for most countries. In the CAFE assessment, two ozone scenarios for 2020 were projected based on current legislation and maximum technically feasible reductions that forecast decreased concentrations with no change in climate. In the current analysis, the possible decrease of ozone precursor emissions and decrease of population in Europe were not taken into account because the goal of the study was to show only the effects of climate change. Our estimates for the UK compare well with estimates by the UK Department of Health [54].

Climate change will also affect other air pollutants, such as particulate matter (PM), although the atmospheric chemistry differs. PM has a stronger (inverse) relationship than ozone to boundary layer height, which is related to wind speed and convective processes. Temperature dependency varies by particle species, with a positive association with sulfates and a possibly negative association with organic species. PM concentrations decrease with increasing precipitation [8]. The effect of climate change on PM is highly uncertain; even the sign differs between studies [8]. Both climate realisations used here simulate decreased precipitation in the south and increased precipitation in the north, increased temperature in all of Europe and decreasing wind speed in southern Europe. This implies that different particulate components will experience future changes of different magnitude and spatial variation.

Several methodological issues may have affected the results. For the time-periods studied, the choice of greenhouse gas emission scenario is not crucially important because the differences in emissions between the scenarios are small prior to 2050. A more important factor is the global climate model used. The downscaling of the two different global climate models reported somewhat different results in different regions of Europe. In most countries, using the HadCM3 global model resulted in higher ground-level ozone baseline values (19611990) compared to ECHAM4. This indicates that in assessing local effects, the choice of global model is important. Also, the climatic variables (such as temperature, humidity, etc.) could affect respiratory hospitalisation rates and thus the impacts of ozone. As the rates are low in mild climate areas such as southern Europe compared to northern Europe, the absolute increase in impacts might be higher than suggested in this study.

These projections can be used in conjunction with projections of changes in emissions under different proposed regulations to understand the magnitude and extent of impacts under a higher temperature future. These projections can also be used by ministries of health and public health organisations to begin planning how to improve current programmes to ensure that vulnerable populations are protected from projected increases in ground-level ozone concentrations in a changing climate.

\section{Conclusions}

The projected effects of climate change on ground-level ozone concentrations could differentially influence mortality and morbidity across Europe. There would be an increase in ozonerelated mortality in southern and central Europe and a slight decrease in northern Europe. Compared to the baseline period (1961-1990), few climate-related ozone impacts appeared in the last two decades (1990-2009), with more projected in the future (2021-2050 and 2041-2060). The HadCM3 global model projected somewhat higher ozone concentrations for the baseline compared to using ECHAM4 in many countries. ECHAM4 gave generally larger health impacts for 2021-2050.

\section{SUPPORT STATEMENT}

This study was supported by the European Union-funded ClimateTrap project (contract EAHC 20081108) and by the Swedish Environmental Protection Agency through the research programme CLEO, Climate Change and Environmental Objectives. H. Orru was supported by grant SF0180060s09 from the Estonian Ministry of Education.

\section{STATEMENT OF INTEREST}

None declared.

\section{REFERENCES}

1 Ayres JG, Forsberg B, Annesi-Maesano I, et al. Climate change and respiratory disease: European Respiratory Society position statement. Eur Respir J 2009; 34: 295-302.

2 US EPA. Assessment of the impacts of global change on regional U.S. air quality: a synthesis of climate change impacts on groundlevel ozone. Washington, DC, USEP Agency, 2009.

3 Andersson C, Engardt M. European ozone in a future climate: importance of changes in dry deposition and isoprene emissions. J Geophys Res 2010; 115: D02303.

4 Andersson C, Langner J, Bergström R. Interannual variation and trends in air pollution over Europe due to climate variability during 1958-2001 simulated with a regional CTM coupled to the ERA40 reanalysis. Tellus B 2007; 59: 77-98.

5 IPCC. Climate Change 2007: The Physical Science Basis Contribution of Working Group I to the Fourth Assessment Report of the Intergovernmental Panel on Climate Change. Cambridge, Cambridge University Press, 2007. 
6 Filleul L, Cassadou S, Medina S, et al. The relation between temperature, ozone, and mortality in nine French cities during the heat wave of 2003. Environ Health Perspect 2006; 114: 1344-1347.

7 Leonardi G, Cooper D, Walton H, et al. Rapid evaluation of 2006 heat wave: epidemiological aspects. London, Health Protection Agency, 2006.

8 Jacob DJ, Winner DA. Effect of climate change on air quality. Atmos Environ 2009; 43: 51-63.

9 Steiner A, Tonse S, Cohen R, et al. The Effects of Climate Change on Biogenic VOCs and Regional Air Quality in California. American Geophysical Union, Fall Meeting, 2005; pp. A32A-02.

10 Pfeiffer M, Kaplan JO. Response of terrestrial $\mathrm{N}_{2} \mathrm{O}$ and $\mathrm{NO}_{x}$ emissions to abrupt climate change. IOP Conf Ser: Earth Environ Sci, 9: 012001.

11 West JJ, Fiore AM, Horowitz LW, et al. Global health benefits of mitigating ozone pollution with methane emission controls. Proc Nat Acad Sci USA 2006; 103: 3988-3993.

12 Westerling AL, Hidalgo HG, Cayan DR, et al. Warming and earlier Spring increase western U.S. forest wildfire activity. Science 2006; 313: 940-943.

13 Pfister GG, Wiedinmyer C, Emmons LK. Impacts of the fall 2007 California wildfires on surface ozone: integrating local observations with global model simulations. Geophys Res Lett 2008; 35: L19814.

14 Anderson $\mathrm{H}$, Atkinson R, Peacock J, et al. Meta-analysis of timeseries studies and panel studies of particulate matter (PM) and ozone $\left(\mathrm{O}_{3}\right)$. Report of a WHO task group. Copenhagen, WHO Regional Office for Europe, 2004.

15 Bell ML, Dominici F, Samet JM. A meta-analysis of time-series studies of ozone and mortality with comparison to the national morbidity, mortality, and air pollution study. Epidemiology 2005; 16: 436-445.

16 Gryparis A, Forsberg B, Katsouyanni K, et al. Acute effects of ozone on mortality from the "air pollution and health: a European approach" project. Am J Respir Crit Care Med 2004; 170: 1080-1087.

17 Ito K, De Leon SF, Lippmann M. Associations between ozone and daily mortality: analysis and meta-analysis. Epidemiology 2005; 16: 446-457.

18 Levy JI, Chemerynski SM, Sarnat JA. Ozone exposure and mortality: an empiric bayes metaregression analysis. Epidemiology 2005; 16: 458-468.

19 Burnett RT, Brook JR, Yung WT, et al. Association between ozone and hospitalization for respiratory diseases in 16 Canadian cities. Environ Res 1997; 72: 24-31.

20 Anderson HR, Spix C, Medina S, et al. Air pollution and daily admissions for chronic obstructive pulmonary disease in 6 European cities: results from the APHEA project. Eur Respir J 1997; 10: 1064-1071.

21 Mortimer KM, Neas LM, Dockery DW, et al. The effect of air pollution on inner-city children with asthma. Eur Respir J 2002; 19: 699-705.

22 Amann M, Bertok I, Cofala J, et al. Baseline scenarios for the Clean Air for Europe (CAFE) programme. Final report. Laxenburg, International Institute for Applied Systems Analysis, 2005.

23 Peters JM, Avol E, Gauderman WJ, et al. A study of twelve Southern California communities with differing levels and types of air pollution. II. Effects on pulmonary function. Am J Respir Crit Care Med 1999; 159: 768-775.

24 Jerrett M, Burnett RT, Pope CA 3rd, et al. Long-term ozone exposure and mortality. N Engl J Med 2009; 360: 1085-1095.

25 Zanobetti A, Schwartz J. Ozone and survival in four cohorts with potentially predisposing diseases. Am J Respir Crit Care Med 2011; 184: 836-841.

26 Chuang KJ, Chan CC, Su TC, et al. The effect of urban air pollution on inflammation, oxidative stress, coagulation, and autonomic dysfunction in young adults. Am J Respir Crit Care Med 2007; 176: 370-376.
27 Hong YC, Lee JT, Kim H, et al. Air pollution: a new risk factor in ischemic stroke mortality. Stroke 2002; 33: 2165-2169.

28 Knowlton K, Rosenthal JE, Hogrefe C, et al. Assessing ozonerelated health impacts under a changing climate. Environ Health Perspect 2004; 112: 1557-1563.

29 Bell M, Goldberg R, Hogrefe C, et al. Climate change, ambient ozone, and health in 50 US cities. Climatic Change 2007; 82: 61-76.

30 Hwang R, Burer M, Bell M. Smog in the forecast: global warming, ozone pollution and health in California. San Francisco, National Resources Defence Council, 2004.

31 Anderson H, Derwent R, Stedman J. Air pollution and climate change. In: McMichael A, Kovats R, eds. Health Effects of Climate Change in the UK. London, Department of Health, 2001; pp. 193-217.

32 West JJ, Fiore AM, Naik V, et al. Ozone air quality and radiative forcing consequences of changes in ozone precursor emissions. Geophys Res Lett 2007; 34: L06806.

33 Chang HH, Zhou J, Fuentes M. Impact of climate change on ambient ozone level and mortality in southeastern United States. Int J Environ Res Public Health 2010; 7: 2866-2880.

34 Tagaris E, Liao KJ, Delucia AJ, et al. Potential impact of climate change on air pollution-related human health effects. Environ Sci Technol 2009; 43: 4979-4988.

35 Doherty RM, Heal MR, Wilkinson P, et al. Current and future climate- and air pollution-mediated impacts on human health. Environ Health 2009; 21: Suppl. 58.

36 Sheffield PE, Knowlton K, Carr JL, et al. Modeling of regional climate change effects on ground-level ozone and childhood asthma. Am J Prev Med 2011; 41: 251-257.

37 Ebi KL, McGregor G. Climate change, tropospheric ozone and particulate matter, and health impacts. Environ Health Perspect 2008; 116: 1449-1455.

38 Anenberg SC, Horowitz LW, Tong DQ, et al. An estimate of the global burden of anthropogenic ozone and fine particulate matter on premature human mortality using atmospheric modeling. Environ Health Perspect 2010; 118: 1189-1195.

39 Robertson L, Langner J, Engardt M. An Eulerian limited-aera atmospheric transport model. J Appl Meteorol 1999; 38: 190-210.

40 Kjellström E, Bärring L, Gollvik S, et al. A 140-year simulation of the European climate with the new version of the Rossby Centre regional atmospheric climate model $\left(\mathrm{RCA}_{3}\right)$. Norrköping, Swedish Meteorological and Hydrological Institute, 2005.

41 Samuelsson $\mathrm{P}$, Jones CG, Willén $\mathrm{U}$, et al. The Rossby Centre Regional Climate model RCA3: model description and performance. Tellus A 2011; 63: 4-23.

42 Engardt M, Bergstrom R, Andersson C. Climate and emission changes contributing to changes in near-surface ozone in Europe over the coming decades: results from model studies. Ambio 2009; 38: $452-458$.

43 Andersson C, Engardt M. European ozone in a future climate: importance of changes in dry deposition and isoprene emissions. J Geophys Res 2010; 115: D02303.

44 Langner J, Engardt M, Andersson C, et al. Modelling the Impact of Climate Change on Air Pollution over Europe Using the MATCH CTM Linked to an Ensemble of Regional Climate Scenarios. Air Pollution Modeling and its Application XXI. The Netherlands, Springer, 2010; pp. 627-635.

45 Langner J, Engardt M, Andersson C. European surface ozone 1990-2100. Atmos Chem Phys 2012; 12: 10097-10105.

46 Kjellström E, Nikulin G, Hansson ULF, et al. 21st century changes in the European climate: uncertainties derived from an ensemble of regional climate model simulations. Tellus A 2011; 63: 24-40.

47 Bell ML, Peng RD, Dominici F. The exposure-response curve for ozone and risk of mortality and the adequacy of current ozone regulations. Environ Health Perspect 2006; 114: 532-536.

48 Amann M, Derwent D, Forsberg B, et al. Health risks of ozone from long-range transboundary air pollution. Copenhagen, World Health Organiziation, Regional Office for Europe, 2008. 
49 Klein Goldewijk K, Beusen A, Janssen P. Long-term dynamic modeling of global population and built-up area in a spatially explicit way: HYDE 3.1. Holocene 2010; 20: 565-573.

50 Committee on the Medical Effects of Air Pollutants. COMEAP Working paper 2002/9a. Is there a threshold for the effect of ozone on health? Is there an effect on mortality and respiratory or circulatory hospital admissions? [working documents] www.dh.gov.uk/prod_ consum_dh/groups/dh_digitalassets/@dh/@ab/documents/digi talasset/dh_096805.pdf Date last updated: May 2002.

51 Nikulin G, Kjellström E, Hansson ULF, et al. Evaluation and future projections of temperature, precipitation and wind extremes over Europe in an ensemble of regional climate simulations. Tellus A, 63: 41-55.

52 WHO. Air quality guidelines: global update 2005. Particulate matter, ozone, nitrogen dioxide and sulfur dioxide. Copenhagen, WHO Regional Office for Europe, 2006.

53 Directive 2008/50/EC of the European Parliament and of the Council of 21 May 2008 on ambient air quality and cleaner air for
Europe. Official Journal of the European Union 2008; L152: $1-44$.

54 Anderson H, Derwent R, Stedman J, et al. The health impact of climate change due to changes in air pollution. In: Kovats R, ed. Health Effects of Climate Change in the UK 2008. An update of the Department of Health report 2001/2002. London, Department of Health, 2008; pp. 91-105.

55 Watkiss P, Pye S, Holland M. CAFE CBA: baseline analysis 2000 to 2020. Brussels, European Commission, 2005.

56 De Marco A. Assessment of present and future risk to Italian forests and human health: modelling and mapping. Environ Pollut 2009; 157: 1407-1412.

57 Bell ML, Davis DL, Gouveia N, et al. The avoidable health effects of air pollution in three Latin American cities: Santiago, São Paulo, and Mexico City. Environ Res 2006; 100: 431-440.

58 Olsson D, Ekström M, Forsberg B. Temporal variation in air pollution concentrations and preterm birth - a population based epidemiological study. Int J Environl Res Public Health 2012; 9: 272-285. 